\title{
THE FINITE ELEMENT ANALYSIS OF OSTEOPOROTIC LUMBAR VERTEBRAL BODY BY INFLUENCE OF TRABECULAR BONE APPARENT DENSITY AND THICKNESS OF CORTICAL SHELL
}

\author{
Oleg ARDATOV*, Algirdas MAKNICKAS"*, Vidmantas ALEKNA***, \\ Marija TAMULAITIENË $\dot{E}^{* * *}$, Rimantas KAČIANAUSKAS**
}

\author{
*Faculty of Mechanics, Department of Biomechanics, Vilnius Gediminas Technical University, Basanavičiaus 28, 03224 Vilnius, Lithuania \\ ${ }^{* *}$ Faculty of Mechanics, Institute of mechanical Science, Vilnius Gediminas Technical University, Basanavičiaus 28, 03224 Vilnius, Lithuania \\ ${ }^{* * *}$ Faculty of Medicine, Vilnius University, Čiurlionio 21, 03101 Vilnius, Lithuania \\ oleg.ardatov@vgtu.It, algirdas.maknickas@vgtu.It, vidmantas.alekna@mf.vu.lt, \\ marija.tamulaitiene@mf.vu.It, rimantas.kacianauskas@vgtu.It
}

received 30 May 2016, revised 22 November 2017, accepted 27 November 2017

\begin{abstract}
Osteoporosis causes the bone mass loss and increased fracture risk. This paper presents the modelling of osteoporotic human lumbar vertebrae L1 by employing finite elements method (FEM). The isolated inhomogeneous vertebral body is composed by cortical outer shell and cancellous bone. The level of osteoporotic contribution is characterised by reducing the thickness of cortical shell and elasticity modulus of cancellous bone using power-law dependence with apparent density. The strength parameters are evaluated on the basis of von Mises-Hencky yield criterion. Parametric study of osteoporotic degradation contains the static and nonlinear dynamic analysis of stresses that occur due to physiological load. Results of our investigation are presented in terms of nonlinear interdependence between stress and external load.
\end{abstract}

Key words: Bone Tissue Elasticity, Finite Element Method, Lumbar Vertebrae, Osteoporosis

\section{INTRODUCTION}

Osteoporosis is a disease characterized by low bone mass and micro-architectural deterioration of bone tissue. Due to the process of osteoporotic degradation, the thickness of cortical bone and apparent density of cancellous bone are significantly reduced. Osteoporosis is one of the major health problems, especially in elderly populations, and is associated with fragility fractures. Various social and medical aspects of the osteoporosis has been studied worldwide (Agarwal and Kalia, 2014; Lin and Lane, 2004, Cooper et al., 2011; Cummings and Melton III, 2002). Although osteoporotic fractures can occur anywhere in the human body, vertebral fractures are the most common among them, particularly in the elderly population. Vertebral fractures result in pain, functional disability, affects the quality of life, and is associated with the increased mortality (Melton III et al., 2013; Johnell et al., 2004).

It could be mentioned that this disease affects over 200 million people over the world. It is estimated that one in three women and one in five men over the age of fifty worldwide will sustain an osteoporotic fracture. Hip and spine fractures are the two most serious fracture types, associated with substantial pain and suffering, disability, and even death. In 2010, 22 million women and 5.5 million men were estimated to have osteoporosis in the European Union; and among 3.5 million new fragility fractures, 520,000 vertebral fractures were sustained. The economic burden of incident and prior fragility fractures was estimated at $€ 37$ billion (Svedbom et al., 2013).

The modern understanding of the osteoporosis has been gained by the cooperative interaction of several scientific disciplines. Apart in depth knowledge of the bone biology, specific understanding of biomechanical behaviour is required. In combination with other studies, the mechanistic approach based on biomechanics and the numerical finite element analysis provide useful tools for research on the bone fragility and support a clinical prediction of bone fractures. The biomechanical research, when compared to the branches of traditional aeronautical and civil engineering, provides not only a new application area but also a raft of challenges relating to the simulation of living tissues. Comprehensive discussion on the role of computational biomechanical simulations was raised up in the review paper (Doblare et al., 2004). The approach integrating numerical simulations, experiments and theoretical knowledge as the major focus of future research was pointed out. Application of computational simulations of factors and parameters that are difficult or impossible to examine experimentally will reduce or even replace experimental and clinical trials.

Adequacy of the finite element simulations essentially depends on the choice of mechanical approach and the development of proper finite model. Generally, mechanical FE simulations are aimed to calculate variations of mechanical stress and strain fields while evaluation of strength, fracture risk and others synonymous parameters is performed in secondary part of simulation.

The FE models applied for mechanical analysis of the spine range from sub-micron scale assessment of vertebral bone up to the analysis of the whole spine and surrounding structures. Developments of the entire human spine scale FE models and their simulations are rather limited (Watanabe et al., 2001; Okamoto et al., 2014). Here, vertebrae are connected via intervertebral 
discs (IVD) and posterior elements having a relatively complex geometry. Numerical results obtained by applying a threedimensional FE model of the human body (Okamoto et al., 2014) illustrate that maximal stresses are distributed along the entire skeleton, but fractures and dangerous deformation are concentrated in the local fragment of three vertebrae. Eight wellestablished FE models of the lumbar spine (L1-L5) created by different research centres around the globe were compared to in vitro and in vivo measurements (Dreischarf et al., 2014).

The earlier developments of spinal finite element models with a view to a standardized framework of verification, validation and sensitivity analysis were examined in the review paper (Jones and Wilcox, 2008). The scope of the above paper was restricted to review models of the vertebra, the intervertebral discs and short spinal segments. Several tendencies concerning various aspects of vertebral models could be distinguished in this review and in the further developments. The FE models largely depend on the material properties, geometry, meshing technique, etc.

Regarding these results and extremely large difficulties in forming of the real geometry of spine, most of the studies focus on the simplified models. Recent developments are limited by smaller fragments of vertebrae (Łodygowski et al., 2005; Su et al., 2009), but majority of the studies concerns vertebral body in isolation (Jones and Wilcox, 2008; Crowford et al., 2003; Maquer et al., 2015; Provatidis et al., 2010), using also the simplified shape by excluding the posterior elements (McDonald et al., 2010; Garo et al, 2011).

Vertebral body under consideration mainly comprises cancellous bone core consisting of the trabecular network surrounded by compact bone in a form of external thin cortical shell. Character of these properties plays crucial role in development of the finite element models. It is obvious that the mechanical properties of the bone tissues in vertebral body are directly influenced by their microstructure (Bono and Einhorn, 2003). Thereby, the measurement of bone mineral density is useful method in evaluation of fracture risk. Osteoporotic changes of the skeleton may be also quantified by the density- dependent bone strength degradation described by power-laws (Doblare et al., 2004). Compressive review and summary of elasticity-density relationships is are also presented by Helgason et al. (2008). Some recommendations are made for the application of elasticity-density relationships to subject-specific finite element studies (Helgason et al., 2008).

Discrete structure of the bone tissue may be transferred to FE models in a number of ways. The voxel-based finite element models are patient-specific or specimen-specific models (Jones and Wilcox, 2008). The sample of vertebral body was generated on the basis of QCT (Crawford et al., 2003). Here, material properties are then defined on an element-by-element basis using densities derived from the scanned image data. This method represents a clinically feasible approach, unable to distinguish properties of the cortical shell. Presented applications illustrate, see (Jones and Wilcox, 2008) and (Crawford et al., 2003), that finite element model-derived estimates of strength are better predictors of in vitro vertebral compressive strength than clinical measurements of bone density using a computer tomography.

A generic FE models are based on continuum description. Characterization of porous discrete micro-structure of trabecular tissues is non-unique and is still under development. The purely elastic inhomogeneous lumbar spine (L3 -L4) model including on the lumbar intervertebral disc, was considered (Su et al., 2009). In Crawford et al., (2003), by imaging observed inhomogeneity was implemented by nine elastic isotropic regions with different elasticity constants. Some of the models include plasticity (Macdonald et al., 2010; Garo et al., 2011). An anisotropic elasticvisco-plastic-damage model was applied by Wolfram et al. (2012).

The two-scale modelling approach proposed in series of works, where the macroscopic constitutive behaviour is determined on the properties of microstructure. Microscopic lattice network is used by McDonald et al. (2010). More comprehensive but computationally expensive approach used in Wierszycki et al. (2014) determines macroscopic constants directly on the detailed geometry of cancellous bone microstructure, where a porous representative cell of trabeculae of a cancellous bone is considered to be 3D solid body.

For identification of loading level and strength of bone the classical continuum-level yield criteria are frequently adopted to the strength criteria. Hereby, the von Mises yield criterion is the mostly used criterion (Provatidis et al., 2010) applied for vertebral trabecular bone. A fabric-dependent, orthotropic Tsai-Wu yield criterion is proposed in Wolfram et al., 2012].

Qualitative verification of the FE models largely depends on the model geometry and meshing technique. Geometry models of vertebrae can be divided into two categories (Jones and Wilcox, 2008). Geometry of models, whose are classified to the first category, is obtained on the data of a particularly measured in vitro specimens and all voxel-based models belong to them. Generic models are computationally generated parametrical models whose values reflect an average of the real sizes. Continuum models of this category are used to represent inhomogeneous vertebra. This approach is basically applied for representation of anatomical geometry of cortical shell. The treatment of the cortical shell by $\mathrm{FE}$ differs across the range of single vertebral models. In several cases, thin (McDonald et al., 2010) or thick (Garo et al., 2011) shell elements may be used but 3D tetrahedral or brick elements still prevail.

Simulation of the spine fragment involves the intervertebral discs (IVD) (Jones and Wilcox, 2008). The IVD presents a complex inhomogeneous, anisotropic and porous structure, which behaviour is governed by biochemical processes as well as mechanical properties. Simulation of the mechanical behaviour of disc has led to a number of different approaches (Dreischarf et al., 2014; Łodygowski et al., 2005; Jaramillo et al., 2015. FE simulation of osteoporotic vertebrae loaded via healthy and degenerated intervertebral disc calibrated against in vitro tests was demonstrated in Crawford et al. (2003). The three different viscoelastic models of disc were considered in Gohari et al. (2013) and three different viscoelastic finite element models were prepared for lumbar motion segment (L4/L5).

In most of applications, the investigations were restricted by static loading, while consideration of the dynamic loads are rather limited (Garo et al., 2011; El-Rich et al., 2009). The present study is aimed at numerical investigating the influence of osteoporotic degradation of $L 1$ lumbar vertebral body on the mechanical strength characterization. Evaluation of the contribution of timedependent load and degradation of mechanical properties is addressed due to dynamic load.

\section{METHODS AND MATERIALS}

\subsection{Problem formulation}

The Von Mises-Hencky criterion is applied on research 
of stresses, which occur on cortical shell of the model. The selection of this criterion is based on mechanical properties of the bone, which seem to behave as a ductile material (Dreischarft et al., 2014; Wolfram et al., 2012).

It is defined in Eq. (1) below, where $\sigma_{1}, \sigma_{2}$ and $\sigma_{3}$ are the maximum, intermediate, and minimum principal stresses respectively. $\sigma_{\mathrm{y}}$ is a yield stress (40 MPa). This value is specific for osteoporotic bone (Nazarian et al., 2008).

$$
\sqrt{\frac{\left(\sigma_{1}-\sigma_{2}\right)^{2}+\left(\sigma_{2}-\sigma_{3}\right)^{2}+\left(\sigma_{3}-\sigma_{1}\right)^{2}}{2}}=\sigma_{\mathrm{y}} \text {. }
$$

In nonlinear dynamic analysis, the equilibrium equations of the dynamic system at time step $t+\Delta t$ are:

$$
\begin{aligned}
& {[M]^{t+\Delta t}\left\{U^{\prime \prime}\right\}^{(i)}+[C]^{t+\Delta t}\left\{U^{\prime}\right\}^{(i)}+} \\
& { }^{t+\Delta t}[K]^{(i) t+\Delta t}\{\Delta U\}^{(i)}={ }^{t+\Delta t}\{R\}-{ }^{t+\Delta t}\{F\}^{(i-1)},
\end{aligned}
$$

where: $[M]$ - mass matrix of the system, $[C]$ - damping matrix of the system, ${ }^{t+\Delta t}[K]^{(i)}-$ stiffness matrix of the system, ${ }^{t+\Delta t}\{R\}-$ vector of externally applied nodal loads, ${ }^{t+\Delta t}\{F\}(i-1)$ - vector of internally generated nodal forces at iteration (i-1), ${ }^{t+\Delta t}[\Delta U]^{(i)}$ - vector of incremental nodal displacements at iteration (i), ${ }^{t+\Delta t}\left\{U^{\prime}\right\}^{(i)}$ - vector of total velocities at iteration (i), $[M]^{i+\Delta t}\left\{U^{\prime \prime}\right\}(i)$ - vector of total accelerations at iteration (i) where damping matrix $[C]$ was neglected or $[C]=0$.

Using implicit time integration Newmark-Beta scheme and employing a Newton's iterative method, the above equations are cast in the form:

${ }^{\mathrm{t}+\Delta \mathrm{t}}[\mathrm{K}]^{(\mathrm{i})}\{\Delta \mathrm{U}\}^{(\mathrm{i})}={ }^{\mathrm{t}+\Delta \mathrm{t}}\{\mathrm{R}\}^{(\mathrm{i})}$,

where: ${ }^{t+\Delta t}\{R\}(i)$ - the effective load vector and ${ }^{t+\Delta t}[K]^{(i)}$ - the effective stiffness matrix.

The three-dimensional static and dynamic analysis was performed using BRIGADE/Plus software.

\subsection{Geometry of the model}

The inhomogeneous lumbar vertebrae body consists of two basic structural members - outer cortical shell fulfilled by inner bone tissue. The initial anatomical geometry of the vertebral body is developed by using DICOM format data and the model is illustrated in Fig. 1. The height of the lumbar vertebral body model is approximately equal to $30 \mathrm{~mm}$, the cross-sectional size is approximately equal to $40 \mathrm{~mm}$. Two intervertebral disks of $10 \mathrm{~mm}$ thickness were also included to reflect boundary conditions with the neighbour trabecular.

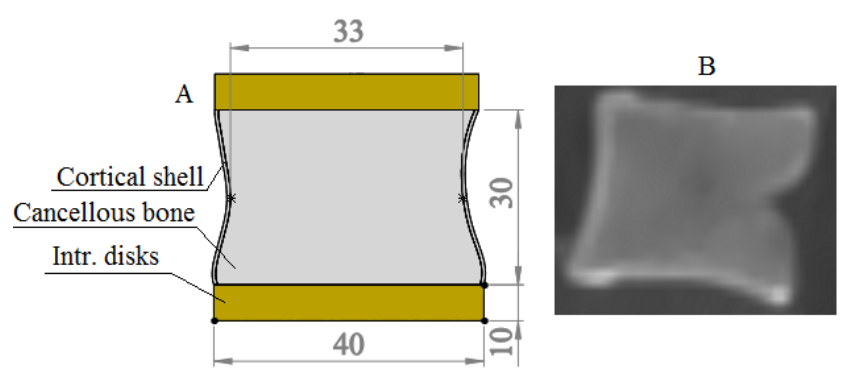

Fig. 1. A) Frontal section view of the model, B) initial DICOM data format (sagittal view)

\subsection{Mechanical properties of structural members}

Surrounding compact bone (cortical shell) is modelled as isotropic elastoplastic continuum as described in McDonald et al., (2010). The inner cancellous bone is transversally isotropic and perfectly elastic. The stress-strain curve for cortical bone is presented in Fig. 2. Intervertebral disks were assumed isotropic and perfectly elastic. Mechanical properties of model members are presented in Tab. 1.

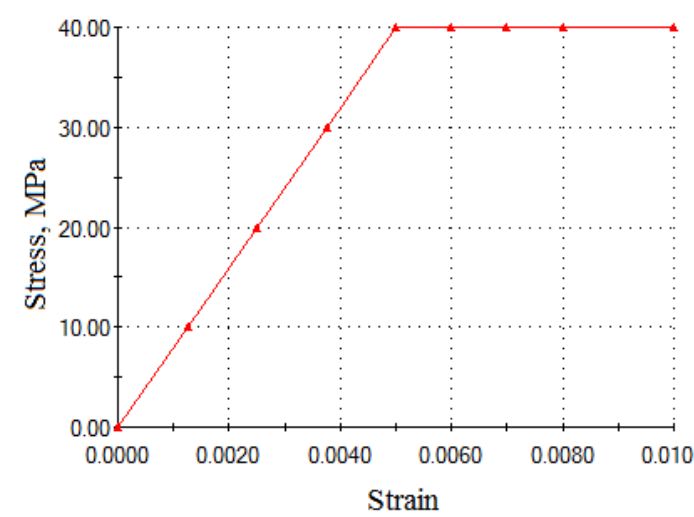

Fig. 2. Stress-strain curve for cortical bone $(E=8 \mathrm{GPa})$

The influence of osteoporosis is modelled by changing the thickness of cortical shell. In this research, we were investigating three models with thickness of $0.2,0.4$ and $0.5 \mathrm{~mm}$ first used in McDonald (2010) and Kim et al. (2013). Osteoporotic changes of the vertebrae is also characterised by decreasing modulus of elasticity of cancellous bone. Modulus of cancellous bone is determined according to power-law equations, which reflect the impact of apparent density. The selection of this equation is based on alignment of our research and data published by Helgason et al. (2008).

$\mathrm{E}_{\text {cancellous }}=4.730 \rho^{1.56}$,

where: $\rho$ - apparent density. In current research, it is in range between 0.10 and $0.30 \mathrm{~g} / \mathrm{cm}^{3}$.

Tab. 1. Elasticity constants and density parameters

\begin{tabular}{|c|c|c|c|c|c|}
\hline $\begin{array}{c}\text { Part of the } \\
\text { model }\end{array}$ & $\begin{array}{c}\mathrm{E}_{\mathbf{z},} \\
\mathrm{MPa}\end{array}$ & $\begin{array}{c}\mathrm{E}_{\mathbf{x}}=\mathrm{E}_{\mathbf{y}}, \\
\mathbf{M P a}\end{array}$ & $\mathbf{V}_{\mathbf{z}}$ & $\mathbf{V}_{\mathbf{x}}=\mathbf{v}_{\mathbf{y}}$ & $\begin{array}{c}\boldsymbol{\rho}, \\
\mathbf{g} / \mathbf{c m}^{3}\end{array}$ \\
\hline Cortical shell & 8000 & 8000 & 0.300 & 0.300 & - \\
\hline $\begin{array}{c}\text { Cancellous } \\
\text { bone }\end{array}$ & $130-$ & $42-240$ & 0.300 & 0.200 & $\begin{array}{c}0.10- \\
0.30\end{array}$ \\
\hline $\begin{array}{c}\text { Intervertebral } \\
\text { disk }\end{array}$ & 10 & 10 & 0.495 & 0.495 & - \\
\hline
\end{tabular}

\subsection{Loads and boundary conditions}

The bone is subjected by the physiological loads, which occur through daily activities. Generally, it presents the axially acting pressure load in the range between 0.15 and $0.75 \mathrm{MPa}$ (Fig. 3). 
These values are equivalent to $160-810 \mathrm{~N}$ compressive force.

Due to nonlinear dynamic analysis, the load depends on the displacement values while it's direction during compression changes with the deformed shape of the model.

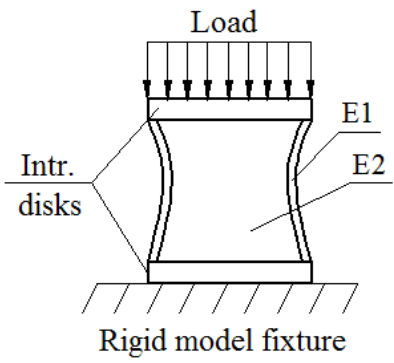

Fig. 3. Schematization of load due to compression test, E1 - cortical shell; E2 - cancellous bone

Time variation of the load is shown in Fig. 4 and is determined to simulate the effect of dynamic load bearing. The character of time curve is based on analysis of jumps using force platform (Linthorne, 2010). It is easy to find that in the first stage until 0.15 $\mathrm{MPa}$ the loading is low and has static character while in the second stage in the range of 0.15 and $0.75 \mathrm{MPa}$ nonlinear behaviour is expected. Load was applied vertically on the surface of superior intervertebral disk. The bottom intervertebral disk was constrained from any motion.

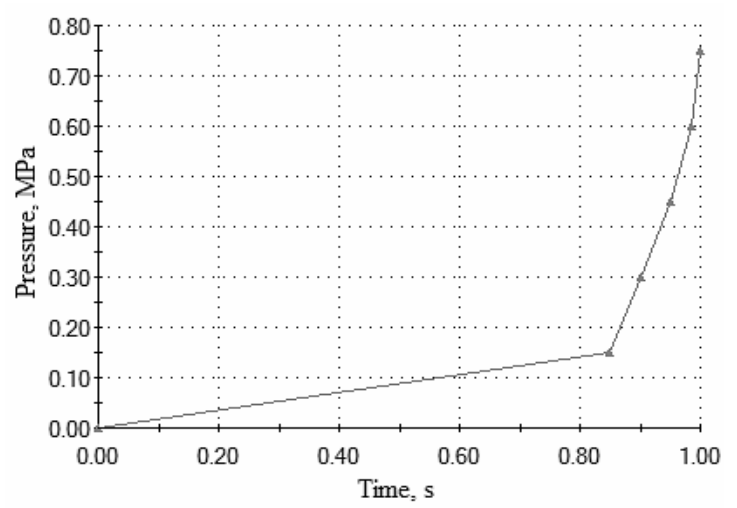

Fig. 4. Variation of dynamic load in time

\subsection{Meshing}

The model was meshed with triangular finite elements due to its curvature. The cortical and trabecular bone is presented as 3D structure and meshed by using volume tetrahedral finite elements. The number of finite elements of cortical bone was 7686 and the number of nodes - 16597, as for the most important part of the model. The number of finite elements of cancellous bone was 12915 , the number of nodes -18313 . The number of finite elements of intervertebral disks was only 3224 and the number of nodes -5677 , for it's not the primary part of the model. The model is characterized by 113274 degrees of freedom. BRIGADE/Plus software was used. The meshed model is presented in Fig. 5.
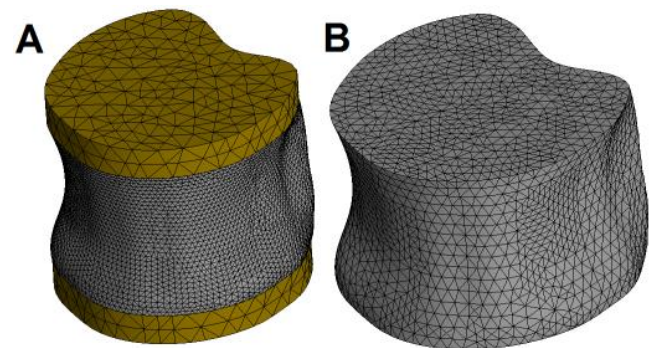

Fig. 5. Meshed parts of the model with finite elements: A) - intervertebral disks and cortical shell, B) - cancellous bone

\section{NUMERICAL RESULTS AND DISCUSSION}

The numerical results of both static, dynamic analysis and their comparison are presented below. Also, the comparison between static and dynamic results is performed and presented graphically.

\subsection{Static analysis}

Stress distribution on cortical shell of the model is shown in Fig. 6. It shows that the highest von-Mises stresses occurred in the middle of the cortical shell on the front side of the model, and on its posterior side (Fig. 6).

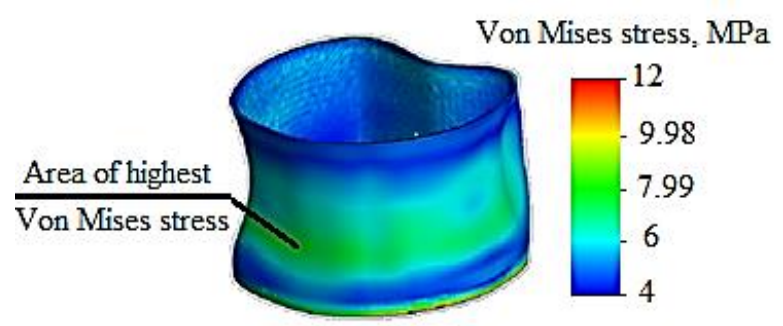

Fig. 6. Distribution of stress on cortical shell of the model under $0.3 \mathrm{MPa}$ load, with apparent density of cancellous bone $0.2 \mathrm{~g} / \mathrm{cm}^{3}$

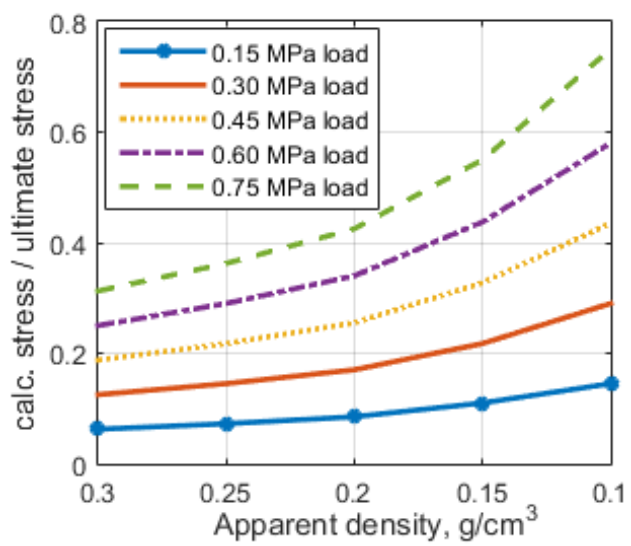

Fig. 7. Relation between calculated and maximum Von Mises stress on cortical shell of the model versus apparent density and load for thickness of cortical shell $0.5 \mathrm{~mm}$

Fig. 7 shows a relation between calculated and ultimate ( $\left.\sigma_{u t}=40 \mathrm{MPa}\right)$ Von Mises stress on cortical shell $(0.5 \mathrm{~mm}$ thickness) of the model versus apparent density and different load 
values. The results show, that maximum calculated stress reaches $70 \%$ of ultimate stress due to $0.75 \mathrm{MPa}$ load on model with apparent density of $0.1 \mathrm{~g} / \mathrm{cm}^{3}$, though, it doesn't reach the value of ultimate stress (40 MPa). It proves that cortical shell plays important role in whole strength of lumbar vertebral body and despite of poor apparent density $\left(0.1 \mathrm{~g} / \mathrm{cm}^{3}\right)$ of cancellous bone, still can carry compression load safely.

Figs. 8 and 9 show a relation between calculated and ultimate Von Mises stress for models with 0.4 and $0.2 \mathrm{~mm}$ cortical shell thickness. Maximal stress is about $35 \mathrm{MPa}$ due to minimum apparent density. It reaches $87 \%$ of ultimate stress and it is $25 \%$ higher than for the model with $0.5 \mathrm{~mm}$ thickness of cortical shell.

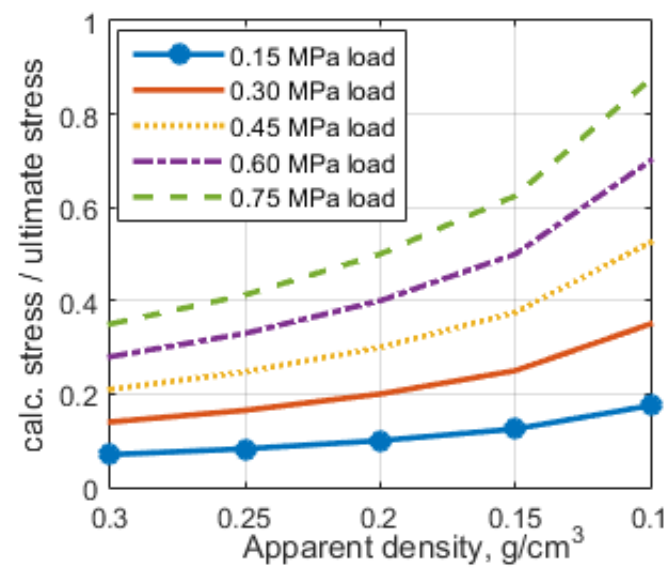

Fig. 8. Relation between calculated and maximum Von Mises stress on cortical shell of the model versus apparent density and load for thickness of cortical shell $0.4 \mathrm{~mm}$

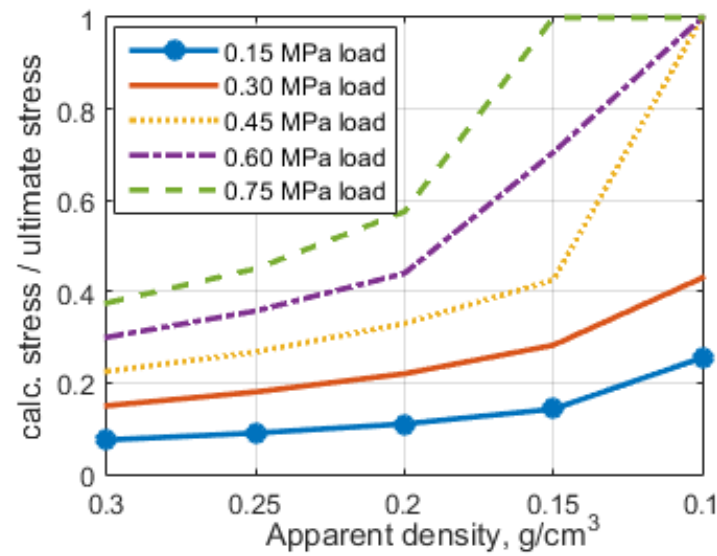

Fig. 9. Relation between calculated and maximum Von Mises stress on cortical shell of the model versus apparent density and load for thickness of cortical shell $0.2 \mathrm{~mm}$

Fig. 9 shows that strength load is $0.45 \mathrm{MPa}$, while apparent density of cancellous bone is less than $0.15 \mathrm{~g} / \mathrm{cm}^{3}$.

Obtained results are in good agreement with research of Kim et al. (2013), with difference about 5-10\% for the model with low apparent density and thickness of cortical shell $0.2 \mathrm{~mm}$. The maximum compressive load for model with $0.2 \mathrm{~mm}$ cortical shell thickness is $0.45-0.60 \mathrm{MPa}$ (in addiction to apparent density), while McDonald (MacDonald et al., 2010) reports this value up to $0.99 \mathrm{MPa}$.

\subsection{Dynamic analysis}

The stresses distribution in lumbar vertebra during dynamical analysis was computed. It is easy to see, that stress concentrators are more contrast, than due to static analysis. The highest value of stress appeared in the middle of cortical shell and it is in a good agreement with clinical observations (Agrawal and Kalia, 2014; Lin and Lane, 2004; Cooper et al., 2011; Cummings and Melton III, 2002; Melton III et al., 2013). The distribution of Von Mises stress on cortical shell of the model is shown in Fig. 10.

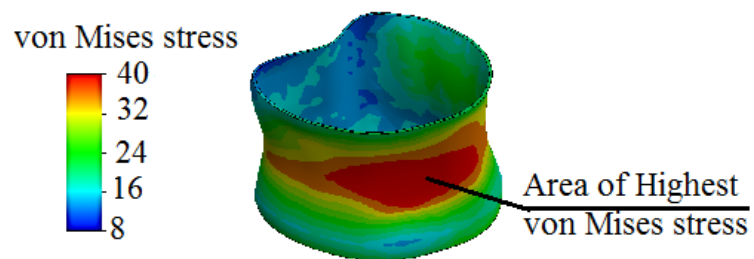

Fig. 10. Distribution of Von Mises stress on cortical shell of the model due to dynamic load

Fig. 11 shows a relation between calculated and maximum ( $\left.\sigma_{\text {ult }}=40 \mathrm{MPa}\right)$ Von Mises stress on cortical shell $(0.5 \mathrm{~mm}$ thickness) of the model versus apparent density and different load values.

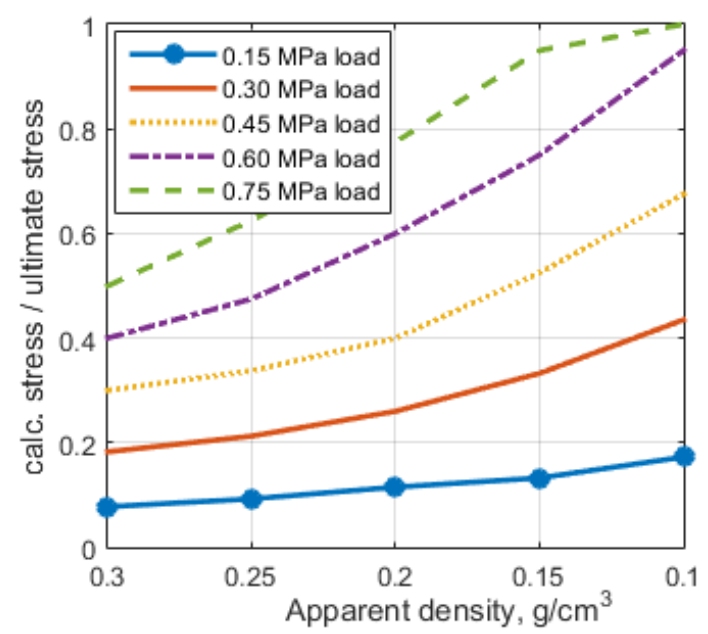

Fig. 11. Relation between calculated and maximum Von Mises stress on cortical shell of the model versus apparent density and load Thickness of cortical shell is $0.5 \mathrm{~mm}$

Fig. 11 shows that failure of the model is expected due to 0.6 $\mathrm{MPa}$ load while density of cancellous bone is less than $0.1 \mathrm{~g} / \mathrm{cm}^{3}$.

Relations between calculated and maximum Von Mises stress on cortical shell of the model with 0.4 and $0.2 \mathrm{~mm}$ thicknesses versus apparent density and load are presented in Figs. 12, 13 and 14. It shows, that failure of the model is expected due to 0.45 MPa load while medium apparent density $\sim 0.2 \mathrm{~g} / \mathrm{cm}^{3}$ occurs. 


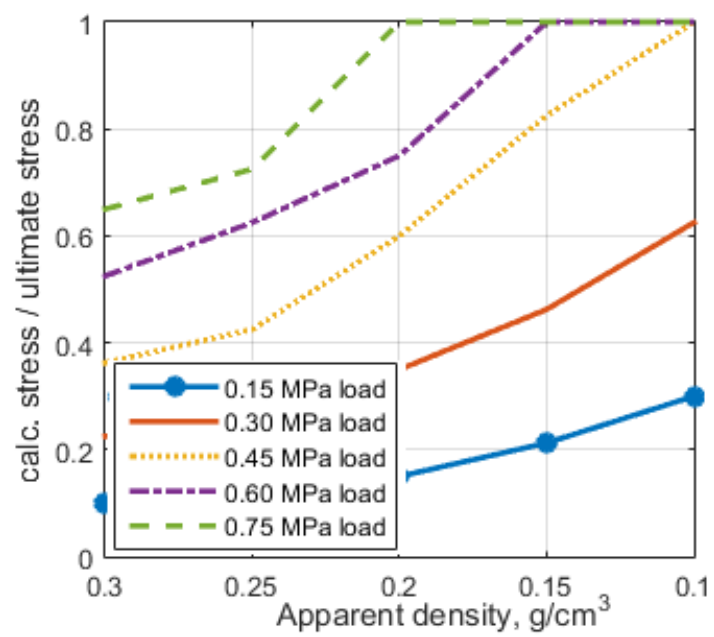

Fig. 12. Relation between calculated and maximum Von Mises stress on cortical shell of the model versus apparent density and load. Thickness of cortical shell is $0.4 \mathrm{~mm}$

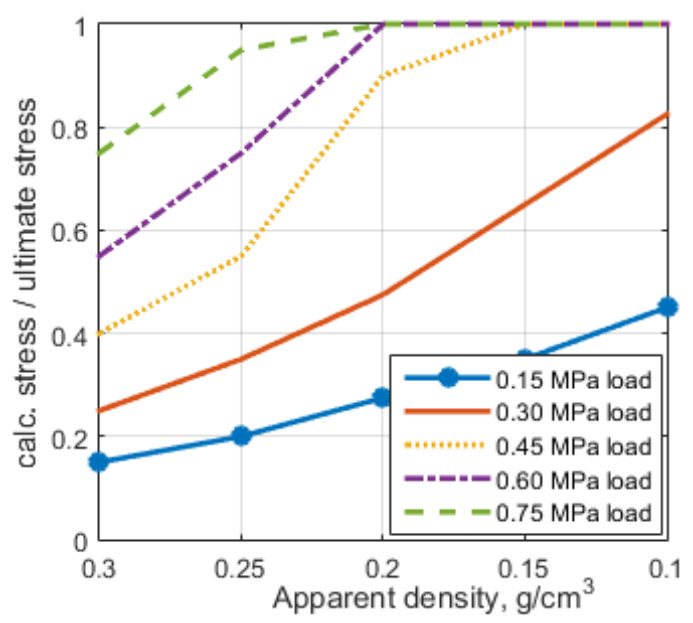

Fig. 13. Relation between calculated and maximum Von Mises stress on cortical shell of the model versus apparent density and load. Thickness of cortical shell is $0.2 \mathrm{~mm}$

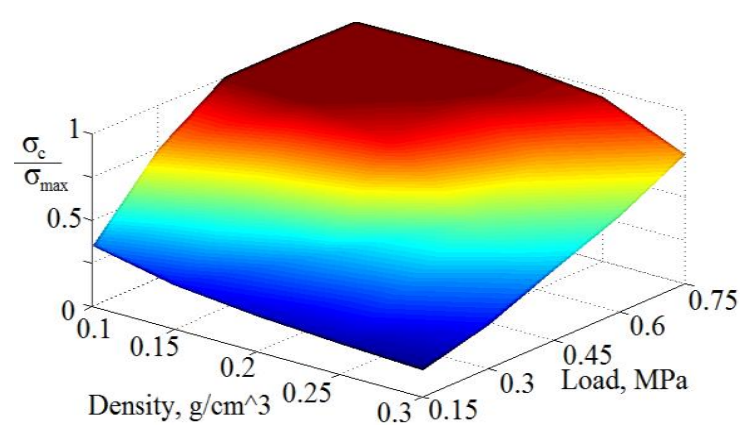

Fig. 14. Relation between calculated and maximum Von Mises stress on cortical shell of the model versus apparent density and load (3D view)

\subsection{Comparison between static and dynamic results}

Distribution of stress due to dynamical load is more varied and there is the higher risk of shell overloading. The failure of the model is obtained by external $0.45 \mathrm{MPa}$ load due to $0.15 \mathrm{~g} / \mathrm{cm}^{3}$ bone density in case of dynamical analysis. The same effect was observed in terms of static analysis, for $0.45 \mathrm{MPa}$ load and 0.10 $\mathrm{g} / \mathrm{cm}^{3}$ cancellous bone density. It shows that dynamic loads are more dangerous for lumbar body (Fig. 15).

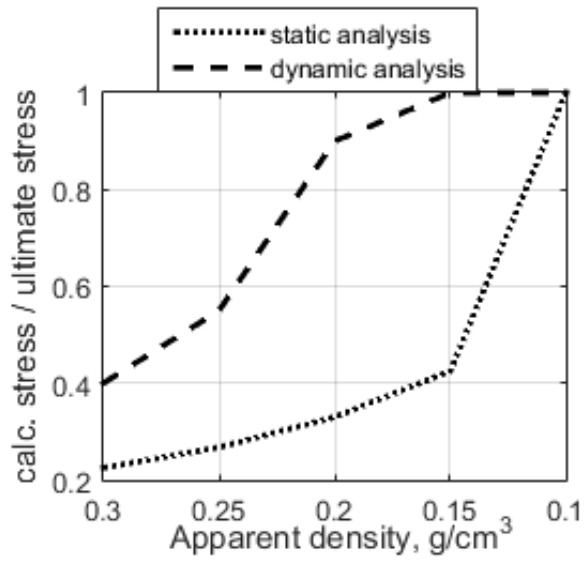

Fig. 15. Dependence between von Mises stress, and density of trabecular bone in model with $0.2 \mathrm{~mm}$ shell thickness due to $0.45 \mathrm{MPa}$ load

The comparison of calculated and ultimate stress in linear static and nonlinear dynamic analysis gives notably higher result for nonlinear dynamics load and is highest for $0.75 \mathrm{MPa}$ and lowest apparent density of trabecular bone $\left(0.1 \mathrm{~g} / \mathrm{cm}^{3}\right)$. It is presented in Figs. 16-18.

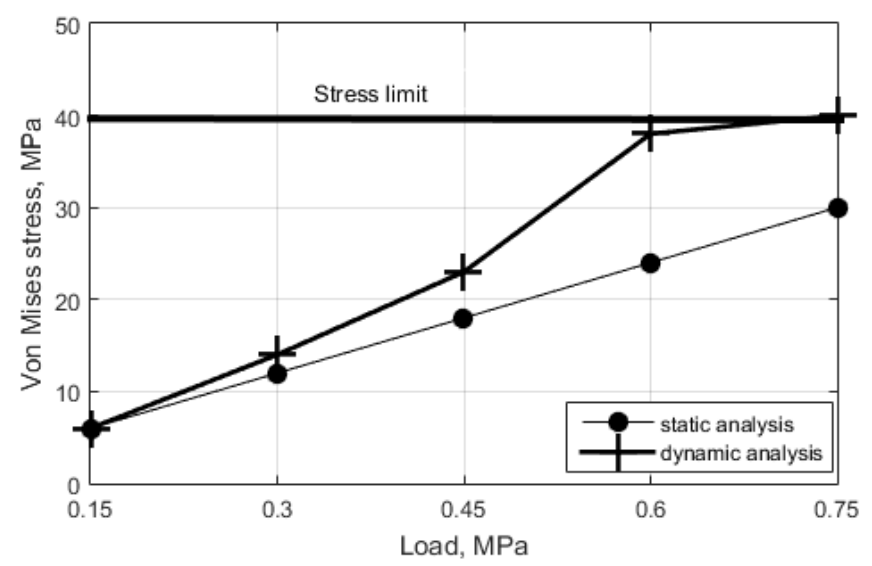

Fig. 16. Difference between Von Mises stress values due to static and dynamic load for model with $0.5 \mathrm{~mm}$ cortical shell thickness

Fig. 16 shows the difference between Von Mises stress values due to static and dynamic load for model with $0.5 \mathrm{~mm}$ cortical shell thickness. Now we observe that the difference between results of static and dynamic analysis increases as load enhances. Ratio between stress values due to $0.45 \mathrm{MPa}$ load is $20 \%$, while it increases up to $40 \%$ due to $0.60 \mathrm{MPa}$ load. Due to 0.75 $\mathrm{MPa}$ load value of stress reaches critical value in case of dynamic load, while the strength capacity is more than $25 \%$ in case of static load.

Fig. 17 shows the difference between Von Mises stress values due to static and dynamic load for model with $0.4 \mathrm{~mm}$ cortical shell thickness. In this case, the ratio between stress values due to $0.15 \mathrm{MPa}$ load is less than $25 \%$ while it reaches $50 \%$ due to $0.45 \mathrm{MPa}$ load, and strength capacity of dynamic load is exceeded, while it has a $15 \%$ reserve due to static load. 


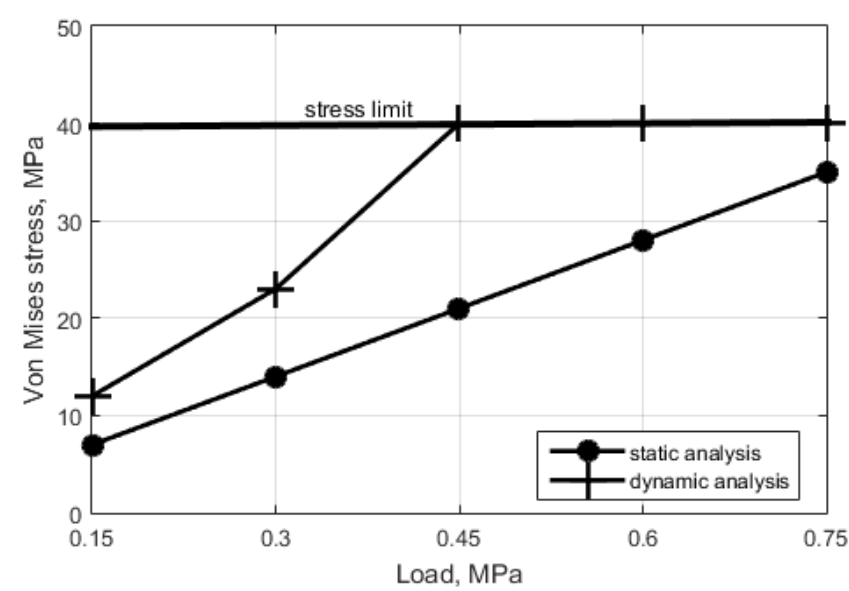

Fig. 17. Difference between Von Mises stress values due to static and dynamic load for model with $0.4 \mathrm{~mm}$ cortical shell thickness

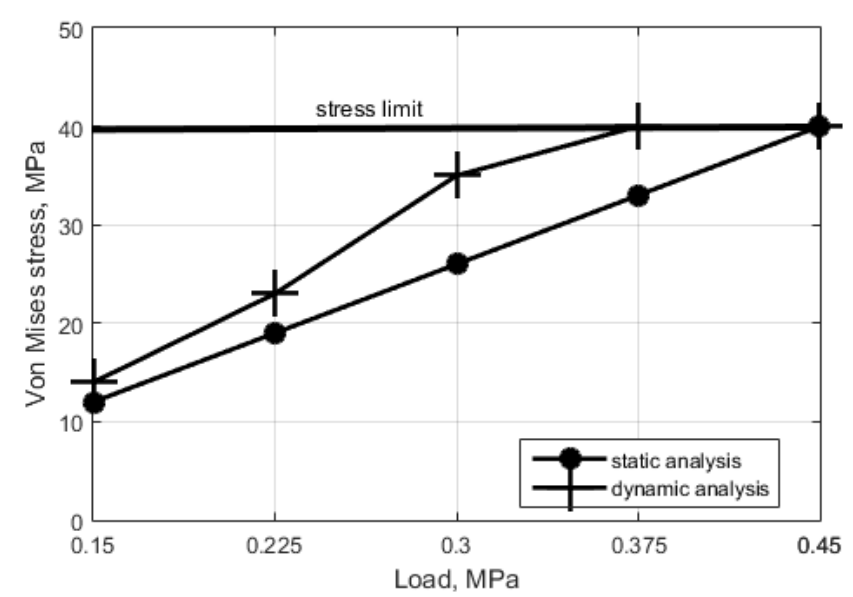

Fig. 18. Difference between Von Mises stress values due to static and dynamic load for model with $0.2 \mathrm{~mm}$ cortical shell thickness

Fig. 18 shows the difference between results of static and dynamic analysis for model with $0.2 \mathrm{~mm}$ thickness of cortical shell. The difference in results exceeds $25 \%$ due to $0.3 \mathrm{MPa}$ load while the difference between stress values due to $0.15 \mathrm{MPa}$ load is only $15 \%$. In both cases critical value of stress is reached due to 0.45 MPa load.

The results obtained also show that stress greatly depends on both thickness of cortical shell and apparent density of cancellous bone, though the primary role is being played by cortical shell, as it carries the major part of the load. On the other hand, a quality of cancellous bone, which is determined by its density, affects the value of stresses. In comparison, the value of failure of the model will be expected due to $0.45 \mathrm{MPa}$ load for model with 0.2 thickness of cortical shell (Fig. 13, 14, 15, 18), since apparent density of cancellous bone is smaller than $0.15 \mathrm{~g} / \mathrm{cm}^{3}$. Also, the results of our research show, that static analysis is not reliable enough for predicting strength capacity of the osteoporotic lumbar vertebrae, with the variance in range of the results up to $50 \%$.

\section{CONCLUSION}

The proposed model which consisted of cortical shell, cancellous bone and intervertebral disks was treated for various grades of degenerative diseases. The numerical test was performed by applying the FEM tools. The problem was solved using tetrahedral finite elements according to complicated curvature of the model. The optimal mesh and number of finite elements were figured up on the basis of calculation accuracy and calculation time ratio. The von-Mises stress, which was assumed to verify the strength properties, was determined for three different thicknesses of cortical shell and different apparent density of cancellous bone (in range of $0.1-0.3 \mathrm{~g} / \mathrm{cm}^{3}$ ).

The results showed that the von-Mises stress was substantially higher under relatively low levels of apparent density, and critical due to thinner cortical shell, which suggests the high fracture risk even during daily activities. The results also showed that cortical shell is the most important component in aspect of lumbar body strength and the decrease of its thickness from $0.5 \mathrm{~mm}$ down to $0.2 \mathrm{~mm}$ leads to bone overloading.

In addition, this model can be individualized according to the peculiar anatomical properties of the patient. For that case the DICOM format file should be extracted and processed using CAD software. Then the mechanical properties based on apparent density should be supplied to the developed model and the numerical results of both static and dynamic loading could be used in order to verify the stressed state of the model.

\section{REFERENCES}

1. Agrawal A., Kalia R. (2014), Osteoporosis: current review, J. Orthop. Traumatol. Rehabil., 7, 101-102.

2. Bono C.M., Einhorn T.A. (2003), Overview of osteoporosis: pathophysiology and determinants of bone strength., Eur. Spine J., 12, 90-96.

3. Bouzakis K.D., Mitsi S., Michailidis N., Mirisidis I., Mesomeris G., Maliaris G., Korlos A., Kapetanos G., Antonarakos P., Anagnognostidos K. (2004), Loading simulation of lumbar spine vertebrae during a compression test using the finite elements method and trabecular bone strength properties, determined by means of nanoindentations, J. Musculoskelet. Neuronal Interact., 4, 152-158.

4. Cooper C., Cole Z.A. Holroyd C.R., et al. (2011), Secular trends in the incidence of hip and other osteoporotic fractures, Osteoporos Int., 22, 1277-1288

5. Crawford R.P., Cann C.E., Keaveny T.M. (2003), Finite element models predict in vitro vertebral body compressive strength better than quantitative computed tomography, Bone, 33, 744-750.

6. Cummings S.R., Melton III L.J.. (2002), Epidemiology and outcomes of osteoporotic fractures, Lancet 359,1761-1767.

7. Doblaré M., García J.M., Gómez M.J. (2004), Modelling bone tissue fracture and healing: a review, Eng. Fract. Mech., 71, 1809-1840.

8. Dreischarf M., Zander T., Shirazi-Adl A., Puttlitz C.M., Adam C.J., Chen C.S., et al. (2014), Comparison of eight published static finite element models of the intact lumbar spine: Predictive power of models improves when combined together, J. Biomech., 47, 1757-1766.

9. El-Rich M., Arnoux P.J., Wagnac E., Brunet C., Aubin C.E. (2009),Finite element investigation of the loading rate effect on the spinal load-sharing changes under impact conditions, J. Biomech., 42, 1252-1262.

10. Garo A., Arnoux P.J., Wagnac E., Aubin C.E. (2011), Calibration of the mechanical properties in a finite element model of a lumbar vertebra under dynamic compression up to failure, Med. Biol. Eng. Comput. 49, 1371-1379.

11. Gohari E., Nikkhoo M., Haghpanahi M., Parnianpour M. (2013), Analysis of different material theories used in a FE model of a lumbar segment motion, Acta Bioeng. Biomech., 15, 33-41.

12. Helgason B., Perilli E., Schileo E., Taddei F., Brynjólfsson S.S., Viceconti M. (2008), Mathematical relationships between bone density and mechanical properties: A literature review, Clin. Biomech., 23, 135-146. 
13. Jaramillo H.E., Gomez L., Garcia J.J. (2015), A finite element model of the L4-L5-S1 human spine segment including the heterogeneity and anisotropy of the discs, Acta Bioeng. Biomeechanics., 17, 15-24.

14. Johnell O., Kanis J.A., Odén A., Sernbo I., Redlund-Johnell I., Petterson C., et al. (2004), Mortality after osteoporotic fractures, Osteoporos. Int., 15, 38-42.

15. Jones A.C., Wilcox R.K., (2008), Finite element analysis of the spine: Towards a framework of verification, validation and sensitivity analysis, Med. Eng. Phys., 30, 1287-1304.

16. Lin J.T., Lane J.M. (2004), Osteoporosis: a review., Clin. Orthop. Relat. Res., 425, 126-34.

17. Linthorne N. P. (2010), Analysis of standing vertical jumps using a force platform, The Journal of Sports Science and Medicine, 9 , 282-287

18. Kim Y.H., Wu M., Kim K. (2013), Stress analysis of osteoporotic lumbar vertebra using finite element model with microscaled beamshell trabecular-cortical structure, Journal of Applied Mathematics, 2013, 146-152.

19. Lodygowski T., Kakol W., Wierszycki M., Ogurkowska B.M. (2005), Three-dimensional nonlinear finite element model of the human lumbar spine segment, Acta Bioeng. Biomech., 7, 17-28.

20. McDonald K., Little J., Pearcy M., Adam C. (2010), Development of a multi-scale finite element model of the osteoporotic lumbar vertebral body for the investigation of apparent level vertebra mechanics and micro-level trabecular mechanics, Med. Eng. Phys., 32, 653-661.

21. Maquer G., Schwiedrzik J., Huber G., Morlock M.M., Zysset P.K. (2015), Compressive strength of elderly vertebrae is reduced by disc degeneration and additional flexion, J. Mech. Behav. Biomed. Mater. 42, 54-66.

22. Melton III L.J., Achenbach S. J. Atkinson E.J., Therneau T.M., Amin S. (2013), Long-term mortality following fractures at different skeletai sites: a population-based cohort study, Osteoporos Int., 24, 1689-1696.
23. Nazarian A., von Stechow D., Zurakowski D., Muller R., Snyder B.D. (2008), Bone Volume Fraction Explains the Variation in Strength and Stiffness of Cancellous Bone Affected by Metastatic Cancer and Osteoporosis, Calcified Tissue International, 83, 368-379.

24. Okamoto Y., Murakami H., Demura S., Kato S., Yoshioka K., Hayashi H., et al. (2014), The effect of kyphotic deformity because of vertebral fracture: a finite element analysis of a $10^{\circ}$ and $20^{\circ}$ wedgeshaped vertebral fracture model, Spine J., 15, 713-720.

25. Provatidis C., Vossou C., Koukoulis I., Balanika A., Baltas C., Lyritis G. (2010),A pilot finite element study of an osteoporotic L1vertebra compared to one with normal T-score., Comput. Methods Biomech. Biomed. Engin., 13, 185-95.

26. Su J., Cao L., Li Z., Yu B., Zhang C., Li M. (2009), Threedimensional finite element analysis of lumbar vertebra loaded by static stress and its biomechanical significance, Chinese $J$. Traumatol., 12, 153-156.

27. Svedbom A., Hernlund E., Ivergård M., Compston J., Cooper C., Stenmark J., McCloskey E.V, Jönsson B., Kanis J.A. (2013), The EU review panel of the IOF. Osteoporosis in the European Union: a compendium of country-specific reports, Arch. Osteoporos., 8, 137138.

28. Watanabe I., Furusu K., Kato C., Miki K., Hasegawa J. (2001), Development of practical and simplified human whole body FEM model, JSAE Rev., 22, 189-194.

29. Wierszycki M., Szajek K., Lodygowski T., Nowak M. (2014), A two-scale approach for trabecular bone microstructure modeling based on computational homogenization procedure, Comput. Mech., 54, 287-298.

30. Wolfram U., Gross T., Pahr D.H., Schwiedrzik J., Wilke H.J., Zysset P.K. (2012), Fabric-based Tsai-Wu yield criteria for vertebral trabecular bone in stress and strain space, J. Mech. Behav. Biomed. Mater., 15, 218-228. 